Article

\title{
The Evolution of Sustainable Business Model Innovation: Evidence from a Sharing Economy Platform in China
}

\author{
Haibo $\mathrm{Hu}^{1}$, Tao Huang ${ }^{2, *}$, Yang Cheng ${ }^{1,2}$ and Haitao $\mathrm{Lu}^{1}$ \\ 1 School of Business Administration, Jiangxi University of Finance and Economics, West Fenglin Street, \\ Economic and Technical Development Zone, Nanchang 330032, China \\ 2 Center for Industrial Production, Aalborg University, Fibigerstraede 16, DK-9220 Aalborg, Denmark \\ * Correspondence: tao@business.aau.dk; Tel.: +45-52731336
}

Received: 19 June 2019; Accepted: 1 August 2019; Published: 3 August 2019

\begin{abstract}
In this paper, we explore the emergence of Sheke Network (SKN), an architecture design company whose network platform permits architecture design institutes to seek suitable architects for their architectural design projects. The concepts of sustainable business model (SBM) innovation are used to analyze the SKN's novel business model, which is built around modern internet technologies, and SKN's distinct appeal, which centers on cost savings, resource sharing, and the potential for access to more architects' experiences. Although SBM innovation theory has had a significant impact on management practices and aroused plenty of rich debate within academia, it is still not clearly understood how a company might successfully build a sharing economy (SE) platform using SBM innovation. Thus, this article analyzes the process of SBM innovation in terms of its three essential factors-sustainable value proposition (SVP), sustainable value creation and delivery (SVC\&D), and sustainable value capture (SVC) - aiming to disambiguate the black box by examining SKN as a case study. The findings highlight the dynamic evolution of SBM innovation in the development of a sharing economy platform.
\end{abstract}

Keywords: SBM innovation; sharing economy platform; value mechanisms; architectural design

\section{Introduction}

The rapid-growth sharing economy (SE) and its dramatic impact on various aspects of today's social economic system have stimulated increased public interest in recent years [1]. The development of the SE in online communities portends significant changes in transportation, tourism, and work locations, among other things. This new business model has been adopted across various industries by many companies (e.g., Airbnb, LendingClub, Uber, Didi, Mobike) that offer a convenient means of "sharing" goods, services, and other resources with the help of digital technology to achieve effective resource allocation and cost saving [2,3]. Unsurprisingly, businesses of the future will continue to be challenged by the dynamism of the economy in which they operate.

Not many SE platforms survive, and few are (or will be) economically successful. These platforms' developmental successes, from start-ups to sustainable businesses, depend on their ability first to mobilize initial user networks, then maintain users' active participation to ensure growth of the userbase that is sufficient for sustainable revenue generation [4]. As a sustainable business model (SBM), the SE has disrupted well-established fields, such as the taxi and hotel industries, by providing low-cost convenience without the responsibility of ownership [5]. Although research on SBM has grown substantially in strategic and innovation management scholarship [6-9], the ways in which they may be successfully designed and implemented merit further exploration. In other words, the 
route to successful implementation of the SBM innovation process remains unclear [10]. Particularly in the context of the SE, our understanding of the SBM innovation process currently appears to be limited [11-13].

In this study, we investigate the case of SKN, which is an SE platform in the architecture design industry that has managed to attract numerous participants to both sides of its platform over the last five years. The main purpose of our study is to shed light on the SBM innovation evolution process of an SE platform and its impact factors. Therefore, in this paper, the research questions are derived as below:

(1) What phases does a sharing economy platform undergo when implementing SBM innovation?

(2) What are the key activities in each of these phases?

(3) What are the main impact factors of SBM innovation on a sharing economy platform?

The remainder of this article is organized as follows: Section 2 provides an exploratory review of selected literature; in particular, the crucial aspects-SE and SBM innovation-will be discussed in detail. This is followed, in Section 3, by a description of the research methodology used in this paper. In Section 4, the case description and analysis are presented. The case study is discussed in Section 5. Finally, in Section 6, the study's theoretical contributions and managerial implications are presented, and both the limitations of our work and possible future research directions are highlighted.

\section{Theoretical Background}

\subsection{Sharing Economy}

In recent years, the rise of the SE has increasingly attracted the attention of academics, policy-makers and the media for its potential to change production and consumption patterns in order to deliver economic, social, and environmental benefits $[14,15]$. The SE has ushered in a new era in which underutilized assets become peer-to-peer (P2P) services for hire, enabled by the internet [16]. However, academic literature has not reached a consensus regarding a universal definition of "sharing economy" [2]. The action of sharing involves "the act and process of distributing what is ours to others for their use and the act and process of receiving or taking something from others for our use" [17]. The term "sharing economy" has also been applied to economic issues, and it goes beyond renting goods at lower costs or with lower transactional overheads than are associated with buying or renting through a traditional provider [18]. Sundararajan [19] defines SE as crowd-based capitalism, since it involves a transfer of ownership through on-demand access. Thus, it has been argued that $\mathrm{SE}$ is closer to an access economy, as the sharing aspect in this context is merely secondary and is market-mediated by an intermediary firm [5]. Additionally, Belk [20] defines collaborative consumption as "people coordinating the acquisition and distribution of a resource for a fee or other non-monetary compensation like bartering, trading, and swapping".

In this paper, we define SE as the monetization of underutilized assets that are owned by service providers (firms or individuals) through short-term rentals [2]. In contrast with the traditional B2B2C (i.e., Business to Business to Consumer) business model, the SE business model of SE consists of three elements: (1) a firm (platform) or service enabler, which acts as an intermediary between (2) the suppliers of a good or service (service provider) and (3) customers who demand those underutilized goods and services (see Figure 1). Specifically, a service enabler (e.g., Uber, Airbnb, Luxe) is set up as an online P2P platform that charges a commission per transaction [21]. Service providers (e.g., driver, host, valet) offer their valuable assets and are personally involved in the transaction, while customers (e.g., rider, guest, consumer) are able to place orders and make payments using this P2P platform. In a traditional B2B environment, there is a dyadic sales relationship between the intermediary firm and the seller (or the buyer), without the need for a direct interaction or transaction between the seller and the buyer. Partners in the supply chain add value to the product or service, as the product or service is transferred between both dyads. However, as a triadic business model, the success of the SE 
platform depends on the assembly of a critical mass of service providers and customers, as well as the service quality [22]. Therefore, the complex nature of the SE platform specifically requires improved understanding of its development.

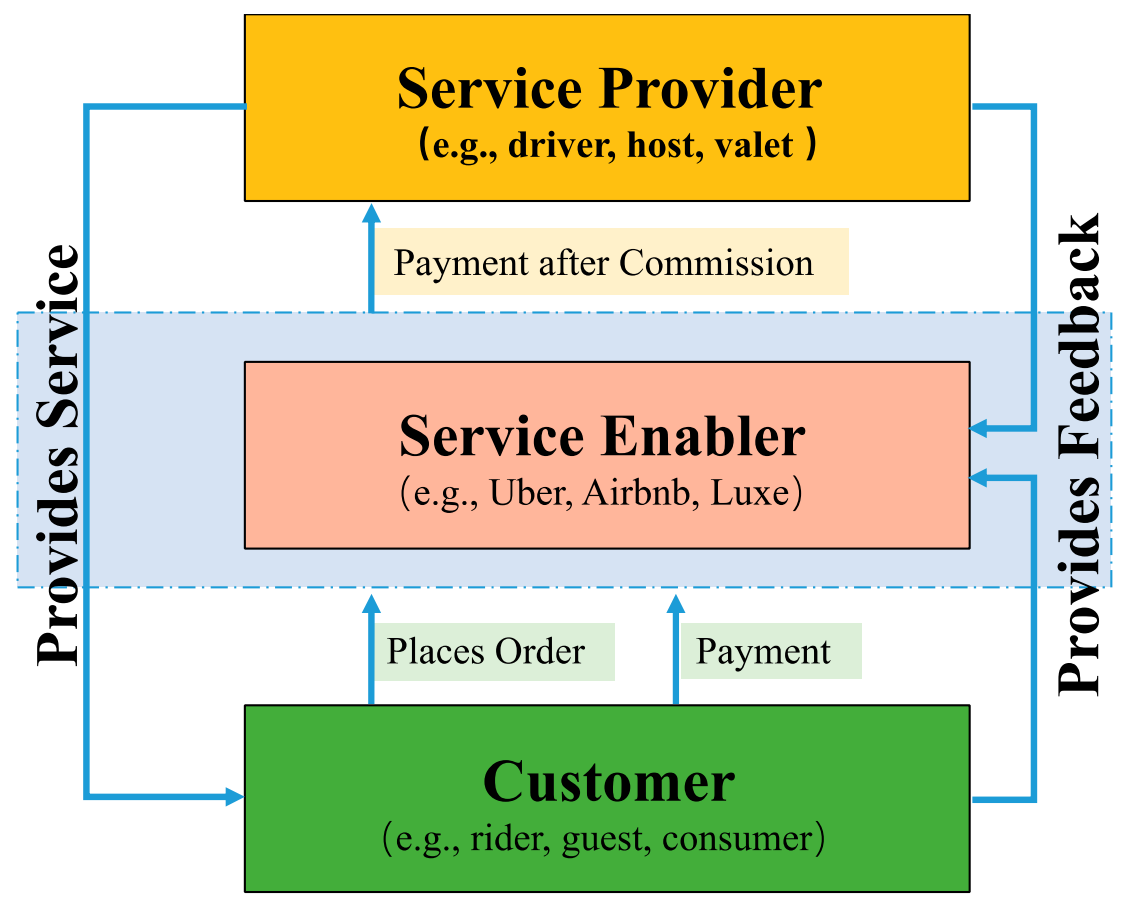

Figure 1. The sharing economy (SE) business model [2].

\subsection{SBM Innovation}

Business models and business model innovation have received substantial attention in literature and industry, and it is increasingly suggested that business model innovation is a key to business success [23-25]. Amidst rising global sustainability pressures, collaboration between firms and other key stakeholders is becoming increasingly important [26]. As such, SBM innovation is increasingly viewed as a lever for systems change in favor of sustainability across several businesses and industries [27,28].

As a subset of the SBM field, research in SBM innovation began relatively recently, and there does not yet appear to be any general consensus regarding its definition in the academic field [10]. Bocken et al. [29] define SBM innovations as innovations that create significant positive and/or significantly reduced negative impacts for the environment and/or society through changes in how the organization and its value-network create, deliver, and capture value (i.e., create economic value) or change their value propositions. SBM innovation, as a form of sustainable innovation, is understood as the adaption of the business model to overcome barriers within the company and its environment to market sustainable process, product, or service innovations [30]. These definitions combine a business model innovation element with sustainability considerations. Similar to scholars' understandings of conventional business model innovation, business model innovation is considered a process of business model exploration, adjustment, improvement, redesign, revision, creation, development, adoption, and transformation [10]. Based on the literature mentioned above, we define SBM innovation as the conceptualization and implementation of new solutions for products, processes, marketing, and/or organization that are embedded in the firm's core business model (the firm's configuration to propose, create, deliver and capture value), in order to improve corporate sustainability performance [31,32]. This may comprise different SBM archetypes, such as maximizing material and energy efficiency, delivering functionality rather than ownership, adopting a stewardship role, and developing scale-up solutions (which are introduced to describe groupings of mechanisms and solutions that may contribute to building up the business model for sustainability) [29]. 
Analogous to the definition of three business model components from a value perspective-value proposition, value creation and delivery and value capture [31,33,34] -SBMs have three main elements: (1) sustainable value proposition (SVP), (2) sustainable value creation and delivery (SVC\&D), and (3) sustainable value capture (SVC) [32]. In the context of SE, sustainable value proposition refers to not only the firm itself, but also the firm's stakeholders beyond the "classical" customer, such as employees, trade associations, suppliers, governments, non-governmental organizations, communities, the environment, and society. During the phase of sustainable value creation and delivery, the main aspects of putting the value proposition into practice are considered. This element encompasses business processes such as primary activities (inbound logistics, production, outbound logistics, marketing and sales, and services) and secondary activities (firm infrastructure, human resource management, information and communication technology, and procurement) [32]. Sustainable value capture concerns consideration of how to earn revenues (i.e., capture value) from the provision of goods, services, or information to users and customers [35]. In the context of SE, sustainable value constitutes value for the firms and their internal and external stakeholders, considering not only short-term impacts, but also long-term consequences [32]. As a pattern of SBM, the sharing economy business model will change over time due to the changes of customers' requirements, markets, technologies, structures, and so on. [36]. According to the differences of value mechanisms and sustainability drivers (e.g., social drivers, economic drivers, environmental and technological drivers), the SBM archetypes will be recognized during the development process of the sharing economy platform [37].

\section{Research Method}

This research presented in this paper employed the exploratory method to gather and analyze the data, aiming at a better understanding of how organizations achieve SBM innovation in a sharing economy platform. As exploratory research, the case study methodology is the most appropriate strategy to address the "how" and "why" questions that guide this article [38,39]. It was also suitable to adopt the single exploratory case study for this research that focused on dealing with a dynamic process under a single context $[38,39]$. We selected the SKN architecture design sharing platform as the case study for three reasons: first, SKN is a typical and representative case in its respective area, revealing a new and special sharing economy phenomenon in the architectural design industry in China's emerging economy; second, we have been following the evolution of SKN from its initiation in 2013, and have collected a rich body of data that allows for an in-depth empirical analysis; finally, it helps us to better understand what constitutes the best practices in the Chinese management context.

To understand SKN's evolution from its beginning as a start-up into a sustainable business, we sought to identify key events and the actions behind those events throughout the firm's history. This study adopted a three-step approach for data collection. First, secondary sources, such as corporate annual reports, press releases, and materials presented to customers were analyzed to provide an overview of the company. Second, as our objective was to generate in-depth insights, we conducted two rounds of semi-structured interviews with the top managers in SKN during January and February 2016 (see Table 1), as well as organizing field trips to SKN that allowed us to obtain facts and opinions about (as well as insights into) phenomena from first-hand sources [39]. Prior to the interviews taking place, protocols were developed to enhance the reliability and validity of the case study data [39]. The interviews each lasted about 1.5-2 h. To ensure reliability, each interview was conducted by two researchers, who recorded and transcribed the information [38], usually within $24 \mathrm{~h}$. After the first round of interviews, the interview guidelines for the second round of interviews were updated based on the initial case data and research framework. Finally, we blended the similar three researchers' perspectives with their valuable different outlooks to formulate a consensus that best matched the case study; thus, we integrated them and formulated the case report in May 2016. Additionally, we sent the case report to SKN for verification. After several iterations, the case report was finalized in July 2016.

Data analysis was carried out simultaneously with data collection, which allowed us to take full advantage of the flexible data collection methods, making relevant adjustments as necessary [38] 
and creating an iterative process through the interviews, literature reviews, and analysis. To ensure validity, the data analysis in this study follows six key steps [40]: transcription, identification of a thematic framework, coding, charting, identification of themes, and mapping and interpretation. In addition, the research relied extensively on triangulation - the use and combination of different methods (documents, interviews and observations) to study the same phenomenon in order to ensure stronger substantiation of constructs and enhance the validity and reliability of the data collected [38].

Table 1. SKN interview list.

\begin{tabular}{cccc}
\hline Interviewee & Frequency & Place & Duration (hours) \\
\hline CEO & 2 & SKN CEO office & 2.5 \\
Design Director & 2 & SKN Design Director office & 2 \\
Operation Director & 1 & SKN Operation Director office & 2 \\
Chief Engineer & 1 & SKN Chief Engineer office & 1.5 \\
Project Manager & 1 & SKN meeting office & 1.5 \\
Market Manager & 1 & SKN meeting office & 1.5 \\
\hline
\end{tabular}

\section{Case Description and Analysis}

\subsection{Overview of Case Background}

The architecture industry is currently one of the five key industries of China's national economy. The architectural design industry has developed rapidly in China, and its overall level has improved considerably; however, architectural design companies are under pressure to transform their business methods as a consequence of the depression of the real estate industry, which has been affected by the tightening of regulations and control policies. As the first to start a network platform for architectural design in China, SKN is dedicated to promoting the sound development of architectural design and helping designers to build entrepreneurial businesses. In recent years, SKN has sought to explore a new and sustainable business model by designing an internet sharing platform, integrating industrial resources, and remodeling the status of the architectural design industry. The development process of SKN has fluctuated, which provided some experience or reference for the small- and medium-sized architectural design institutes in China.

As a network sharing platform for architectural designers, SKN has brought significant changes to traditional architectural design companies. It is increasingly recognized that SKN's innovation - particularly in relation to the sustainable digital platform phenomenon-is a key issue for discussion. In this paper, we will describe the evolution of SBM innovation in the process of building a sharing economy platform through four phases: the birth, implementation, growth, and adjustment of SKN.

\subsection{Phase 1: Birth of SKN (July-November 2015)}

The Chinese economy has recently undergone enormous changes, particularly in the context of Internet Plus, and companies face several new challenges during the ongoing transformation process. To our knowledge, the architectural design industry consistently follows the pace of rapid development trends in the real estate industry. Meanwhile, the architectural design industry is facing a new challenge with regard to resource integration: "According to the relevant statistics (http://www.chyxx.com), by the end of 2013, the number of registered national architecture design engineers was 2.44 million, and it was 3.8 million in 2014. Besides, there is still a large number of registered survey and design industry practitioners, the per capita annual output of survey design industry is 30 thousand per person. It is expected that the number of national architecture design engineers will reach about 6 million in 2015. And the growth rate will maintain 15 20\% every year", as recounted by Mr. Xu, the CEO of SKN.

To some extent, the proliferation of architectural design engineers has directly contributed to the vigorous development of the architectural design industry. It has not only greatly improved the 
overall image of the architecture field, but has also promoted real estate sales and development and enhanced the domestic architecture field's core competitiveness in the international market. At the same time, architectural design has veered away from the traditional sector and fixed-design model to the personalized, free-design model. Architectural design engineers not only pursue income, but also care about design inspiration and free development space.

Because of the frequent poor configuration of architecture design projects and idle resources of designers, an overcapacity has emerged in the industry, whereby most small- and medium-sized architecture design institutes face crises of bankruptcy or reorganization. In the context of the supply and demand contradiction of the architectural design industry, Mr. Xu began seeking a solution to these difficult conditions in July of 2015.

"Even though currently our company (Jiangxi Good Architectural Design Company, Nanchang, China) has a stable business, we have to think ahead about the industry's situation and consider industry risk prevention measures for the future", explained Mr. Li, SKN's operations director. Therefore, based on the company's existing human, market, and financial resources, Mr. Xu proposed the establishment of a kind of internet network to help small- and medium-sized architectural design institutes integrate the resources of architectural design enterprises, which will eventually become an integrated platform based on capital sharing, project collaboration, and data sharing.

In September of 2015, SKN was founded in Nanchang, Jiangxi Province, China. At this early stage of SKN's network creation, the cumulative growth in the number of guests that used the design offered through SKN's platform was slow but steady. At the end of November 2015, 300 architectural designers were registered on SKN's platform. Several actions responding to emerging problems in internal platform tests or providing incremental improvements to existing functions of the platform were taken.

\subsection{Phase 2: Implementation of SKN (December 2015-February 2016)}

In recent years, the issue of overcapacity in the architecture industry has become increasingly prominent. According to Mr. Tian, the project manager, “The small- and medium-sized architectural design institutes are facing two major difficulties. First, due to the geographical constraints and other reasons, there are not enough outstanding designers working for the institutes, thus, the design projects cannot achieve the state of optimal resource allocation; second, a part of designers cannot find enough design projects, which directly leads to the waste of designers resources." SKN was officially online and open to the entire public in December of 2015, which helped stakeholders of architectural design projects, such as the architectural design engineers and institutes, to achieve information communication, business interaction, and coordination of design. During this phase, SKN focused on building the supply side of the network based on the platform's internal testing in the first phase, with particular emphasis on actions that proved added value, introducing more and more architectural design institutes for designers. At that time, the Chinese government also introduced several helpful policies to encourage people to do business creatively and drive innovation in the context of Internet Plus, which provided a sound development environment for internet platforms such as SKN.

As Mr. Li-the operations director of SKN—described: "The establishment of SKN has experienced four key stages. First, based on the analysis of the SKN project background, SKN seized the designers' demands for starting a business, and committed to building a resource service platform. The designers of SKN can obtain a stable source for design projects, a wealth of learning materials, and opportunities for communication between partners and peers. Second, considering the position of SKN's products, SKN took "PACKAGE and SHARING" as the core concept, and carried out the intelligent matching with the talent pool, which consists of designers and project resources provided by architecture design institutes. Third, based on the analysis of SKN's competitive advantages, SKN explored the competitiveness of the platform in two dimensions of architectural designers and design institutes; from the point of the designers, SKN may increase their revenue, improve their design ability, and supply them the freedom to the work time arrangement and the choice of design projects; from the 
view of the design institutes, SKN can expand their business, reduce their operation costs and motivate the enthusiasm of their staff. Fourth, in terms of SKN's strategy, SKN development strategies are made with the perspective of market layout and product planning. In February of 2016, SKN chose Beijing as the location of its headquarters, and Nanchang as a test field, then gradually extended to second-tier cities of China." So far, SKN has been a platform linking design institutes and designers throughout China (as shown in Figure 2).

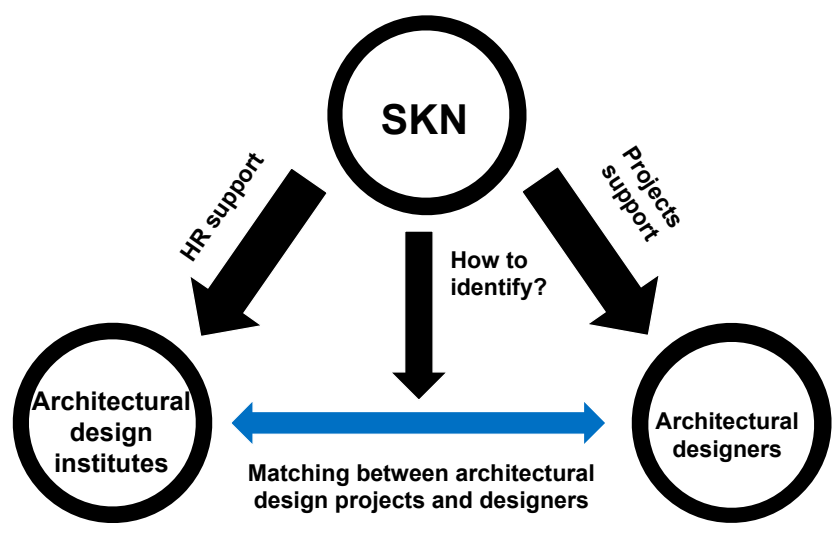

Figure 2. The relationship between the three main subjects of SKN.

\subsection{Phase 3: Growth of SKN (March-September 2016)}

By the end of March 2016, after seven months of the platform's development, the platform had grown from a start-up sharing network of architectural design institutes willing to offer their projects (and architectural designers interested in completing these projects) to a larger platform with 700 architectural designers and 50 design institutes. This far exceeds the scale of a provincial design institute. Just as Mr. Wang, a Chief engineer at SKN, observed, "SKN (1.0 Version) is a kind of resource sharing platform by creating information communication, business interaction, and design coordination between designers and design agencies" (as shown in Figure 3). Design institutes upload design manuscripts or drawings, requirements for designers, and other related specifications to the network platform. The designers can update their status, design features, and design backgrounds within the network platform membership system. They not only can search for design projects, but also request information relating to the projects from the platform's intelligent matching system.

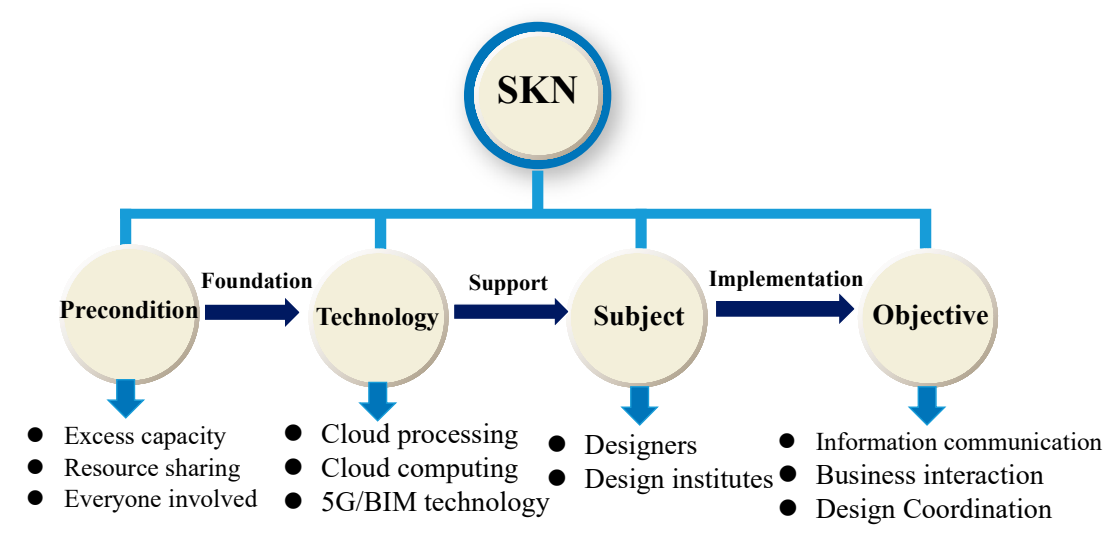

Figure 3. Characteristics of SKN'S sharing economy platform.

At this stage, SKN continued building the platform by offering the trusteeship service of the platform's funds. A cooperation agreement with China Construction Bank was signed, which ensured the financial security of the platform design services for both architectural design institutes and designers. Meanwhile, SKN also introduced Jiangxi Zhongbo Engineering Consulting Company and 
Jiangxi Ganjian Engineering Construction Supervision Company as third-party technical certification institutions, not only to fully protect the privacy of customers but also to ensure the legitimate rights and interests of the designers and design institutes. As explained by Miss Wang, the market manager of SKN, "To date, according to the functions of the platform, SKN achieves a win-win result for the architectural design institutes and designers by reallocating all kinds of resources from different parts. More specifically, SKN provides the design institutes with the support of the project and human resources. And the designers can share a vast amount of technical information to make a better communication with other peers. Sometimes the platform holds some accurate technical training activates to designers according to their needs online or offline, which improves the ability of designers a lot."

Moreover, SKN adopts different information technologies to link the designers and design institutes with the aim of building a cloud design platform, which consists of collaborative design technology, cloud processing, cloud computing, and so on. Thus, this platform breaks the technological barriers to designers' remote communications and builds a technical docking platform between designers so that the whole project design process can be continuously updated in the cloud.

Regarding the project subcontracting process (as shown in Figure 4), the project manager, Mr. Tian, described it as follows:

"SKN links the projects pool and designers' storage by the cloud design platform, achieving the matching between design projects from the design institutes and designers from different areas of China. Once the design projects are subcontracted to the designers, SKN tracks all relevant information and data of the design projects in the cloud platform, then it can coordinate the problems encountered in the progress of the design projects to ensure the effective operation of the whole design industry chain."

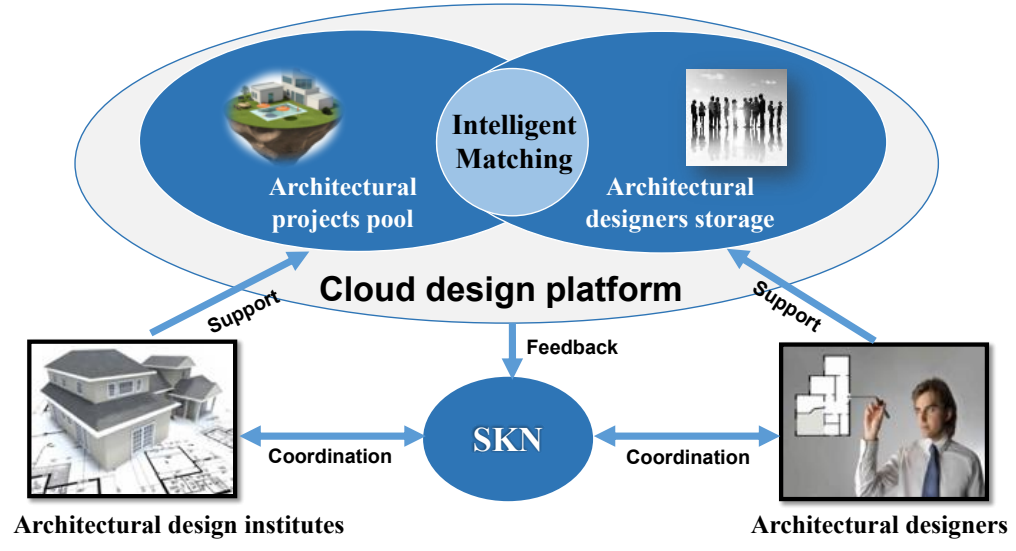

Figure 4. The process of project subcontracting.

\subsection{Phase 4: Adjustment of SKN (October 2016-Present)}

After the growth phase, SKN attracted more and more design institutes and designers to join the platform, and started to extend its strategic actions in different directions. In October 2016, SKN introduced the annual membership model, whereby newly registered designers on the platform were liable for an annual fee of RMB 200. If the registered designers recommended five architectural designers who met the network platform's requirements for registration, the annual fee would be waived. If the registered designers invited 10 more designers who satisfied the platform's requirements, they would receive a chance to secure free lifetime use of the platform. At the same time, the 2.0 version of SKN was launched, which continued to offer incremental improvements and value-adding services; for example, it constantly optimized the user's experience and improved the interface and functional applications. At the business level, SKN attempted to introduce some real estate development companies with the aim of expanding the entire industrial chain of the architectural design. Mr. Xu, the CEO of SKN, observed: 
"In terms of long-term development, SKN follows the "three-step" business strategy, namely translating the stage from a professional architectural design service platform to an open cooperation platform that incorporates designers and all other related architectural design resources, finally achieving an architectural design industry ecosystem with the guidance of the development philosophy 'delivering love through design'. Up to now, SKN has stayed in the first stage of the professional architectural design service platform. More specifically, the designers work more freely without the limitations of time and space, and the storage and delivery issues of massive databases are proceeded by the platform of SKN."

Furthermore, at this stage, a new review system was launched with the aim of motivating the design institutes to provide honest feedback to the designers and increase the quality of the reviews that they saw on the designers' listings and profile pages. Now, every guest of the platform could see the completed design reviews after both involved parties had completed their assessments of the design service. SKN also conducted follow-up services for each design project based on the evaluations. On the one hand, every design project could be successfully completed within the expected time. On the other hand, the rights of both the architectural designers and design institutes could be protected.

As observed in the case description and analysis, SKN experienced a series of actions and challenges in the process of building an architectural design sharing platform. In the next section, we discuss these findings and detail the contributions of our study.

\section{Discussion}

SKN has managed to assemble a large userbase, incorporating an impressive number of architectural design institutes and designers and transforming from a start-up into a sustainable business in China. Our analysis of SKN indicates that SBM innovation in the context of a sharing economy platform is a dynamic evolution process that consists of four phases: the birth, implementation, growth, and adjustment of the platform (as shown in Table 2). In the next four subsections, we discuss the main differences in the evolution of SBM innovation from the aspects of SBM archetype, platform structure, value mechanism, and impact factors (summarized in Table 2).

Table 2. The evolution process of SBM innovation on a sharing economy platform.

\begin{tabular}{|c|c|c|c|c|}
\hline $\begin{array}{l}\text { SBM Innovation } \\
\text { Phase }\end{array}$ & Birth of Platform & $\begin{array}{c}\text { Implementation of } \\
\text { Platform }\end{array}$ & Growth of Platform & $\begin{array}{l}\text { Adjustment of } \\
\text { Platform }\end{array}$ \\
\hline SBM Archetype & $\begin{array}{l}\text { Maximize internal } \\
\text { resources efficiency }\end{array}$ & $\begin{array}{l}\text { Widely deliver platform } \\
\text { service }\end{array}$ & $\begin{array}{l}\text { Adopt a platform } \\
\text { stewardship role }\end{array}$ & $\begin{array}{l}\text { Develop scale-up } \\
\text { solutions }\end{array}$ \\
\hline \multicolumn{5}{|l|}{ Platform Structure } \\
\hline Value Mechanism & $\begin{array}{ll}\text { - } & \text { SVP1 } \\
\text { - } & \text { SVC\&D1 } \\
\text { - } & \text { SVC1 }\end{array}$ & $\begin{array}{ll}\text { - } & \text { SVP2 } \\
\text { - } & \text { SVC\&D2 } \\
\text { - } & \text { SVC2 }\end{array}$ & $\begin{array}{ll}- & \text { SVP3 } \\
\text { - } & \text { SVC\&D3 } \\
\text { - } & \text { SVC3 }\end{array}$ & $\begin{array}{ll}\text { - } & \text { SVP4 } \\
\text { - } & \text { SVC\&D4 } \\
\text { - } & \text { SVC4 }\end{array}$ \\
\hline Impact Factors & $\begin{array}{l}\text { - } \\
\text { - } \quad \text { EF: comtrepreneurship }\end{array}$ & $\begin{array}{ll}\text { - } & \text { IF: team } \\
\text { - } & \text { EF: } \\
& \text { political environment }\end{array}$ & $\begin{array}{ll}\text { - } & \text { IF: } \\
\text { strategy adjustment } \\
\text { - } & \text { EF: financial and } \\
& \text { technical support }\end{array}$ & $\begin{array}{l}\text { - IF: platform } \\
\text { users database } \\
\text { EF: supply } \\
\text { chain development }\end{array}$ \\
\hline
\end{tabular}

Note: The dotted circle represents no direct contact. The meanings of the letters in the figures are as follows: $\mathrm{P}$, platform; D, designer; DI, design institute; FI, financial institution; ES, engineering supervision; RE, real estate; SVP, sustainable value proposition; SVC\&D, sustainable value creation and delivery; SVC, sustainable value capture; IF, internal factors; EF, external factors. The numbers (i.e., 1, 2, 3, 4) represent the different value mechanisms of SBM innovation. In the platform structure, the yellow circle represents the involvement of new customers (i.e., FI, ES); the blue circle represents the involvement of new service providers (i.e., RE); and the circles in different colors reflected the evolution of platform stakeholders. 


\subsection{Birth: Maximize Internal Resources Efficiency}

As mentioned above, based on the existing resources of the company called Good, SKN initially focused on the creation of both sides of its platform: the architectural designers and design institutes (see Table 2). They attempted to build an internal sharing platform aimed at maximizing efficiency with regard to the internal designer resources. From the perspective of the value mechanism, the designers could access more opportunities to participate in the design projects according to their abilities. On the other hand, SKN achieved a higher profit and a competitive pricing advantage, as the costs were reduced through the optimized use of designer resources (summarized in Table 3).

Such a strategic action in the first phase was affected by the entrepreneurship of the CEO, who exercised insight regarding long-term development. In addition, pressure from the competition in China's architectural design market was growing, while the external effects of the unbalanced relationship between architectural design projects and designers were also significant for the birth of SKN. Therefore, in the birth phase of an SE platform, an important objective of SBM innovation is "maximizing internal resources efficiency" runs through the entire business and subsequently enhances the value proposition (e.g., improving resource efficiency and reducing waste of human resource cost). With the driving of entrepreneurship, this SBM archetype seeks to mitigate the environmental impact of external competition in the architectural design industry by reducing waste of internal architectural designers resources.

Table 3. The characteristics of SBM innovation in Phase 1.

\begin{tabular}{cl}
\hline Phase 1 & \multicolumn{1}{c}{ Content Description/Definition } \\
\hline $\begin{array}{c}\text { Maximize Internal Resources } \\
\text { Efficiency }\end{array}$ & $\begin{array}{l}\text { Do more with fewer internal architectural designer resources, } \\
\text { generating less waste of human resource. }\end{array}$ \\
\hline & SVP: Services that use fewer internal architectural designer \\
resources, resulting in less waste of HR cost.
\end{tabular}

\subsection{Implementation: Widely Deliver Platform Service}

As mentioned above, in the first phase of the development of SKN, it only served the architectural designers from its own company, Jiangxi Good Architectural Design Company, China. However, SKN was opened to the public in the second phase, and more and more architectural designers and design institutes registered with the platform. The augmentation of SKN's platform showed impact factors from two aspects. From SKN's internal perspective, it is clear that SKN had a stable team that supported the platform's entire operation process, as more and more architectural designers from different regions in China joined this platform. From the external perspective, it was particularly clear that the relaxing of the nation's political environment allowed the rapid development of Internet Plus business. Therefore, the services provided by the designers could better match the requirements of the design institutes.

In terms of the value mechanism, it was key to facilitate more direct contact between architectural designers and design institutes (see Table 2). As shown in Table 4, SKN engaged in the development of a platform scale aimed at integrating the entire architectural design supply chain. This also enabled consumers (e.g., architectural design institutes) to access appropriate design services in terms of cost, 
thus expanding the design market potential of new innovations. This SBM archetype is about shifting substantially towards the pure service model-that is, it may incentivize the architectural designers to develop the design for reparability and upgradability, potentially better living up to architectural design institutes' expectations for designs. Such SBM innovation changes traditional consumption patterns by developing a more open platform, breaking the simple relationship of $\mathrm{B} 2 \mathrm{C}$, as the platform structure in Table 2 shows.

Table 4. The characteristics of SBM innovation in Phase 2.

\begin{tabular}{|c|c|}
\hline Phase 2 & Content Description/Definition \\
\hline $\begin{array}{l}\text { Widely Deliver Platform } \\
\text { Service }\end{array}$ & $\begin{array}{l}\text { Provide services that satisfy the needs of both architectural designers and } \\
\text { design institutes. }\end{array}$ \\
\hline \multirow{3}{*}{ Value Mechanism } & $\begin{array}{l}\text { SVP: Provide services that satisfy users' needs. Business focus shifts } \\
\text { from an internal sharing platform to public, so more users can benefit from } \\
\text { the platform. }\end{array}$ \\
\hline & $\begin{array}{l}\text { - SVC\&D: Delivery through design service offerings require significant } \\
\text { changes within the firm to deliver this and may incentivize design for } \\
\text { reparability and upgradability. Potentially, more direct contact between } \\
\text { architectural designers and design institutes. Supply chains become more } \\
\text { integrated. }\end{array}$ \\
\hline & $\begin{array}{l}\text { SVC: Consumers pay for the use of the service in a more open platform. } \\
\text { This can enable consumers to access suitable services while considering cost, } \\
\text { thus expanding the design market potential of new innovations. }\end{array}$ \\
\hline Impact Factors & $\begin{array}{l}\text { - Internal factor: team } \\
\text { - External factor: political environment }\end{array}$ \\
\hline
\end{tabular}

\subsection{Growth: Adopt a Platform Stewardship Role}

During the third phase of the platform service level's augmentation, to generate long-term business benefits for the platform, SKN followed an "adopting a platform stewardship role" strategy (see Table 5), alternating its focus and efforts on different members of the platform. It was a process that saw gradual incremental changes and improvements to platform capabilities and associated practices over time. As mentioned above, SKN introduced China Construction Bank to ensure the financial security of the platform, which enhanced the trust between the platform and its users. In addition, in terms of the design technology and design project management, the connection between the third-party technical certification institutions and the platform was established, and different information technologies to link the architectural designers and design institutes were adopted with the aim of establishing a cloud design platform. On the other hand, to enhance the designers' potential, SKN organized several professional seminars and training events via online and offline methods. It was apparent that the platform's participants had changed from dualism to pluralism (summarized in Table 2).

Based on the favorable internal and external factors detailed above (summarized in Table 5), SKN engaged with all users and other related stakeholders to ensure their long-term well-being and database security, which was reflected in the value mechanism of the third phase (summarized in Table 5). Specifically, as the platform structure in Table 2 shows, SKN not only effectively integrated suppliers and customer resources, but also introduced more relevant stakeholders such as financial support institutions and technical supervision organizations, which provided effective supports for financial security and technical standards. In doing so, and "adopting a platform stewardship role", this SBM archetype engaged the improvement of the platform management service level by expanding auxiliary functions, which enhanced the brand service value of the platform. 
Table 5. The characteristics of SBM innovation in Phase 3.

\begin{tabular}{|c|c|}
\hline Phase 3 & Content Description/Definition \\
\hline $\begin{array}{l}\text { Adopt a Platform } \\
\text { Stewardship Role }\end{array}$ & $\begin{array}{c}\text { Proactively engaging with all stakeholders to ensure their long-term well-being and } \\
\text { database security. }\end{array}$ \\
\hline \multirow{3}{*}{ Value Mechanism } & $\begin{array}{l}\text { SVP: Provision of services intended to genuinely and proactively engage with } \\
\text { stakeholders and ensure their long-term well-being and database security. Broader } \\
\text { benefits to stakeholders often become an important aspect of the value proposition by } \\
\text { better engaging the consumer with the full story of the service and the supply chain. }\end{array}$ \\
\hline & $\begin{array}{l}\text { SVC\&D: Ensuring activities and partners are focused on delivering stakeholder } \\
\text { well-being and database security. To achieve scale, use of third-party certification may } \\
\text { facilitate implementation and monitoring. }\end{array}$ \\
\hline & $\begin{array}{l}\text { SVC: Stewardship strategies can generate brand value and potential for premium } \\
\text { pricing. Stakeholder well-being and database security generate long-term business } \\
\text { benefits for the platform. }\end{array}$ \\
\hline Impact Factors & $\begin{array}{l}\text { - Internal factor: strategy adjustment } \\
\text { - External factor: financial and technical support }\end{array}$ \\
\hline
\end{tabular}

\subsection{Adjustment: Develop Scale-Up Solutions}

After the growth phase, the 2.0 version of SKN was launched, focusing on the development of scale-up solutions based on the combinations of the aforementioned SBM archetypes. Regarding the platform, SKN constantly optimized the user experience, improved the interface and functional application, and attempted to add new functions of service, such as a review system. Having grown into a viable business, a large portion of the user database and the platform's mature supply chain system were formed. The overall strategy shifted towards more sustainable solutions for the platform's users, which were extended upstream (e.g., real estate companies) of the architecture design industry (see Table 2). Thus, it ensured that the platform could achieve scale by adding potential partners. Naturally, the platform accessed more profit space through a fixed charge, such as the annual fee, which was clearly a completely different value mechanism, as summarized in Table 6 .

"Developing scale-up solutions"- this SBM archetype was used to consider the scale-up and widespread presence of the sharing economy platform for sustainable development. Based on the big platform user database and supply chain development, the sharing economy platform adopted this archetype for achieving its own transformation, which was envisaged to provide assistance in scaling up a solution and delivering sustainable value for the whole architectural design industry.

Table 6. The characteristics of SBM innovation in Phase 4.

\begin{tabular}{cl}
\hline Phase 4 & \multicolumn{1}{c}{ Content Description/Definition } \\
\hline Develop Scale-Up Solutions & $\begin{array}{l}\text { Delivering sustainable solutions at a large scale to maximize benefits for } \\
\text { the platform. }\end{array}$ \\
\hline Value Mechanism & $\begin{array}{l}\text { SVP: Scaling sustainability solutions to maximize benefits of the } \\
\text { whole industry chain. }\end{array}$ \\
\cline { 2 - 3 } the right channels and partnering with others. New and potentially \\
unusual partners are required to scale the business.
\end{tabular}




\section{Conclusions}

\subsection{Theoretical Contributions}

In this study, we investigated how a start-up sharing economy platform became a sustainable business. Our case analysis revealed four distinct development phases in its evolution: birth, implementation, growth, and adjustment. Our case study demonstrated how SBM innovation evolved throughout the construction of a sharing economy platform, and identified the main impact factors of its evolution. Based on the theory of SE and SBM innovation, further discussion about the process of SBM innovation has been offered, and a new theoretical framework for the SBM innovation process is proposed (as shown in Figure 5).

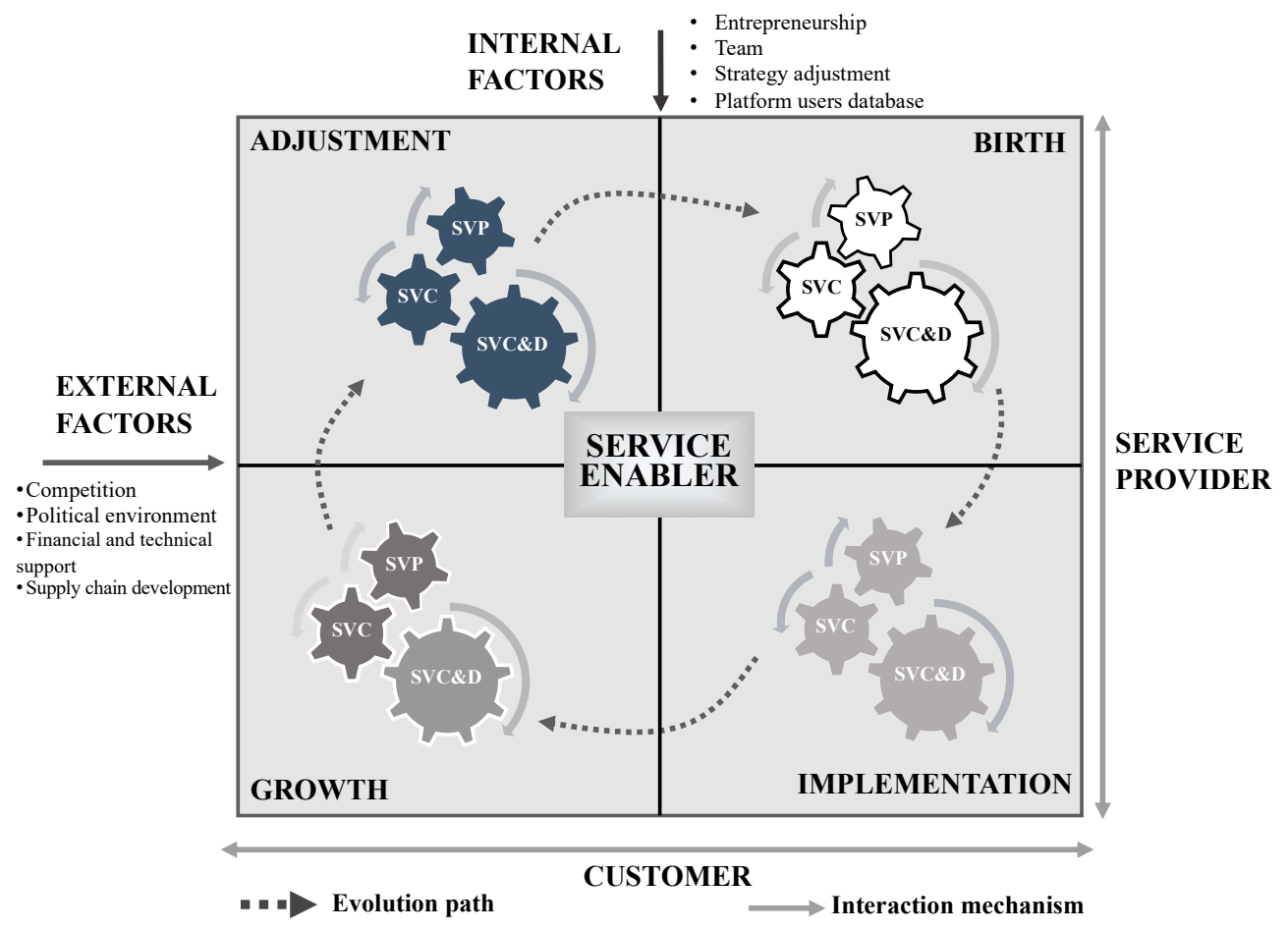

Figure 5. Dynamic SBM innovation process.

The three main theoretical contributions of this study are as follows. First, within this basic outline (see Figure 5), the SBM innovation process constitutes a rhythm of searching and selecting, and exploring and experimenting, with cycles of divergent and convergent thinking, which helps us better understand the complex and interactive process of the sharing economy platform that is composed of three main units: service enablers, service providers, and customers. Clearly, members of the platform structure also represent a diversified trend as the platform scale develops (see Table 2). Specifically, the sharing economy platform is the service enabler in the whole SBM innovation process. The customer has finally shifted from the single structure (i.e., architectural design institutes) to dual structure (i.e., architectural design institutes and real estate developers), and in addition to architectural designers as the service providers of the platform, the service providers are supplemented by financial institutions (i.e., banks) and technical supervision services (i.e., engineering supervision) during the growth phase of the sharing economy platform.

Second, this circular development process of SBM innovation is an interdependent system based on the concepts of SVP, SVC\&D, and SVC [32,41]. During each distinct SBM innovation phase, these three aspects of value mechanism interact with and influence each other. As the discussion above indicates, this also reflects the fact that the value mechanisms in the four evolution process are quite different. In addition, the main impact factors of SBM innovation on SKN's sharing economy platform 
were recognized based on the discussion of value mechanisms. SBM innovation was influenced by two aspects: (1) internal factors, such as entrepreneurship, team, strategy adjustment, and platform user database; and (2) external factors, such as competition, political environment, financial and technical support, and supply chain development factors [42], which corresponded to the value mechanisms of the four distinct SBM innovation stages.

Third, our findings show that the SBM archetypes in the four innovation processes differ in response to the different platform structures and value mechanisms. Specifically, in the four SBM innovation phases, the categorization of four SBM archetypes are defined as: maximizing internal resource efficiency, widely delivering platform service, adopting a platform stewardship role, and developing scale-up solutions. This evolution path of SBM innovation has reflected the practical transformation mechanisms emerging to deliver architectural design industrial sustainability in China. Within each of these SBM innovation phases, there may be a degree of adjustment in value mechanisms and various platform structure members, which provide assistance in seeking new ways to create and deliver sustainable value.

\subsection{Managerial Implication}

Despite the significance of SBM innovation, the process of developing an SE platform remains elusive to many firms. We hope that our findings from the case study will provide some practical implications so that more firms may better understand how an SE platform can contribute to sustainable development through a firm's sustainable value proposition and the adoption of methods for sustainable value creation, delivery, and capture. We learned that it is especially significant for traditional companies to achieve SBM innovation. This research developed a theoretical framework for SBM innovation that could guide companies through the SBM innovation process by mapping key activities and potential challenges. This would also lead to the adoption of more sustainable solutions in industry development and the generation of greater customer benefits, shareholder value, and economic growth.

\subsection{Limitations and Future Research}

Our study was subject to two limitations. First, our research was a qualitative generalization process based on the case study, and the researchers' prejudices and biases in gathering and inferring the interview data and collecting information of a subjective nature may have influenced the research process. Future research could consider adopting quantitative analysis methods to further verify propositions. Second, this paper only reviewed a single case from the architectural design industry to discuss the evolution of SBM innovation; future research may focus on companies from other industries (e.g., the education and transportation sectors) to extend our understanding of how SBM innovation might be achieved.

Author Contributions: H.H. was responsible for the design of the whole research; T.H. analyze the case data and wrote the paper. Y.C. gave valuable advices for the revision. H.L. collected the case data.

Funding: This research was funded by the National Social Science Foundation of China (Grant No. 15BGL033) and a scholarship from the State Scholarship Fund awarded by the China Scholarship Council (No. 201608360117).

Acknowledgments: The authors would like to thank the reviewers and the editor for their insightful comments, which helped improve the quality of the paper significantly.

Conflicts of Interest: The authors declare no conflict of interest.

\section{References}

1. Cheng, M. Sharing economy: A review and agenda for future research. Int. J. Hosp. Manag. 2016, 57, 60-70. [CrossRef]

2. Kumar, V.; Lahiri, A.; Dogan, O.B. A strategic framework for a profitable business model in the sharing economy. Ind. Mark. Manag. 2018, 69, 147-160. [CrossRef] 
3. Roma, P.; Panniello, U.; Nigro, G.L. Sharing economy and incumbents' pricing strategy: The impact of Airbnb on the hospitality industry. Int. J. Prod. Econ. 2019, 214, 17-29. [CrossRef]

4. Constantiou, I.; Eaton, B.; Tuunainen, V.K. The evolution of a sharing platform into a sustainable business. In Proceedings of the 49th Hawaii International Conference on System Sciences (HICSS), Koloa, HI, USA, 5-8 January 2016.

5. Eckhardt, G.M.; Bardhi, F. The sharing economy isn't about sharing at all. Harv. Bus. Rev. 2015, $28,2-4$.

6. Arevalo, J.A.; Castello, I.; de Colle, S.; Lenssen, G.; Neumann, K.; Zollo, M. Introduction to the special issue: Integrating sustainability in business models. J. Manag. Dev. 2011, 30, 941-954. [CrossRef]

7. Boons, F.; Montalvo, C.; Quist, J.; Wagner, M. Sustainable innovation, business models and economic performance: An overview. J. Clean. Prod. 2013, 45, 1-8. [CrossRef]

8. Schaltegger, S.; Lüdeke-Freund, F.; Hansen, E.G. Business cases for sustainability: The role of business model innovation for corporate sustainability. Int. J. Innova. Sustain. Dev. 2012, 6, 95-119. [CrossRef]

9. Svensson, G.; Wagner, B. Business sustainability: Frameworks and cases. Eur. Bus. Rev. 2011, $23,4$. [CrossRef]

10. Geissdoerfer, M.; Vladimirova, D.; Evans, S. Sustainable business model innovation: A review. J. Clean. Prod. 2018, 198, 401-416. [CrossRef]

11. Chesbrough, H. Business model innovation: It's not just about technology anymore. Strategy Leadersh. 2007, 35, 12-17. [CrossRef]

12. Foss, N.J.; Saebi, T. Fifteen years of research on business model innovation. J. Manag. 2017, 43, $200-227$. [CrossRef]

13. Teece, D.J. Reflections on "profiting from innovation". Res. Policy 2006, 35, 1131-1146. [CrossRef]

14. Martin, C.J. The sharing economy: A pathway to sustainability or a nightmarish form of neoliberal capitalism? Ecol. Econ. 2016, 121, 149-159. [CrossRef]

15. Piscicelli, L.; Ludden, G.D.; Cooper, T. What makes a sustainable business model successful? An empirical comparison of two peer-to-peer goods-sharing platforms. J. Clean. Prod. 2018, 172, 4580-4591. [CrossRef]

16. Cusumano, M.A. How traditional firms must compete in the sharing economy. Comm. ACM. 2015, 58, 32-34. [CrossRef]

17. Belk, R. Why not share rather than own? Ann. Am. Acad. Political Soc. Sci. 2007, 611, 126-140. [CrossRef]

18. Zervas, G.; Proserpio, D.; Byers, J. A First Look at Online reputation on Airbnb, Where Every Stay Is above Average. Working Paper of SSRN. Available online: http://ssrn.com/abstract=2554500 (accessed on 26 February 2015).

19. Sundararajan, A. The Sharing Economy: The End of Employment and the Rise of Crowd-Based Capitalism; MIT Press: Cambridge, MA, USA, 2016.

20. Belk, R. You are what you can access: Sharing and collaborative consumption online. J. Bus. Res. 2014, 67, 1595-1600. [CrossRef]

21. Tussyadiah, I.P. Factors of satisfaction and intention to use peer-to-peer accommodation. Int. J. Hosp. Manag. 2016, 55, 70-80. [CrossRef]

22. Rochet, J.C.; Tirole, J. Platform competition in two-sided markets. J. Eur. Econ. Assoc. 2003, 1, 990-1029. [CrossRef]

23. Chesbrough, H. Business model innovation: Opportunities and barriers. Long Range Plan. 2010, 43, 354-363. [CrossRef]

24. Zott, C.; Amit, R.; Massa, L. The business model: Recent developments and future research. J. Manag. 2011, 37, 1019-1042.

25. Parida, V.; Sjödin, D.; Reim, W. Reviewing literature on digitalization, business model innovation, and sustainable industry: Past achievements and future promises. Sustainability 2019, 11, 391. [CrossRef]

26. Lowitt, E. The Collaborative Economy; Jossey-Bass (Wiley): San Francisco, CA, USA, 2013.

27. Yip, A.W.; Bocken, N.M. Sustainable business model archetypes for the banking industry. J. Clean. Prod. 2018, 174, 150-169. [CrossRef]

28. Presenza, A.; Messeni Petruzzelli, A.; Natalicchio, A. Business model innovation for sustainability. Highlights from the tourism and hospitality industry. Sustainability 2019, 11, 212. [CrossRef]

29. Bocken, N.M.; Short, S.W.; Rana, P.; Evans, S. A literature and practice review to develop sustainable business model archetypes. J. Clean. Prod. 2014, 65, 42-56. [CrossRef] 
30. Björkdahl, J.; Holmén, M. Business model innovation-The challenges ahead. Int. J. Prod. Dev. 2013, 18, 213-225.

31. Osterwalder, A.; Pigneur, Y.; Tucci, C.L. Clarifying business models: Origins, present, and future of the concept. Commun. Assoc. Inf. Syst. 2005, 16, 1-25. [CrossRef]

32. Morioka, S.N.; Evans, S.; de Carvalho, M.M. Sustainable business model innovation: Exploring evidences in sustainability reporting. Procedia CIRP 2016, 40, 659-667. [CrossRef]

33. Osterwalder, A.; Pigneur, Y. Business Model Generation: A Handbook for Visionaries, Game Changers, and Challengers; John Wiley \& Sons: Hoboken, NJ, USA, 2010.

34. Richardson, J. The business model: An integrative framework for strategy execution. Strateg. Chang. 2008, 17, 133-144. [CrossRef]

35. Teece, D. Business models, business strategy and innovation. Long Range Plan. 2010, 43, 172-194. [CrossRef]

36. Daunorienè, A.; Drakšaitè, A.; Snieška, V.; Valodkienè, G. Evaluating sustainability of sharing economy business models. Proc. Soc. Behav. Sci. 2015, 213, 836-841. [CrossRef]

37. Demailly, D.; Novel, A.S. The sharing economy: Make it sustainable. Studies 2014, 3, 14-30.

38. Eisenhardt, K.M. Building theories from case study research. Acad. Manag. Rev. 1989, 14, 532-550. [CrossRef]

39. Yin, R.K. Case Study Research: Design and Methods, 5th ed.; Sage Publications: Thousand Oaks, CA, USA, 2014.

40. Lacey, A.; Luff, D. Qualitative Data Analysis; Trent Focus Group: Sheffield, UK, 2001.

41. Adner, R.; Kapoor, R. Value creation in innovation ecosystems: How the structure of technological interdependence affects firm performance in new technology generations. Strateg. Manag. J. 2010, 31, 306-333. [CrossRef]

42. Assink, M. Inhibitors of disruptive innovation capability: A conceptual model. Eur. J. Innov. Manag. 2006, 9, 215-233. [CrossRef]

(C) 2019 by the authors. Licensee MDPI, Basel, Switzerland. This article is an open access article distributed under the terms and conditions of the Creative Commons Attribution (CC BY) license (http://creativecommons.org/licenses/by/4.0/). 